\title{
A COMPARATIVE STUDY OF THE TWO DIFFERENT DOSES OF INTRATHECAL HYPERBARIC (0.5\%) BUPIVACAINE PLUS FIXED DOSE FENTANYL FOR LOWER ABDOMINAL SURGERY
}

\author{
ARVIND BHALEKAR ${ }^{a}$, RAJEEV KUMAR DUBEY ${ }^{\text {11 }}$, P. SHARMA ${ }^{\mathrm{c}}$ AND ANIL KUMAR PASWAN

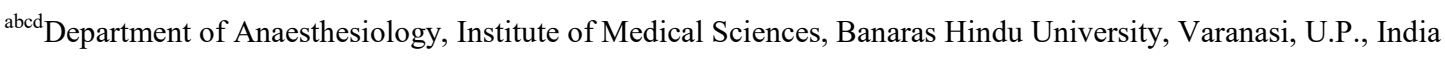

\begin{abstract}
A randomised prospective study was carried out to compare intrathecal 12.5 and $10 \mathrm{mg}$ hyperbaric bupivacaine with fixed dose of $25 \mu \mathrm{g}$ fentanyl in lower abdominal surgery.In the present study, 60 patients belonging to ASA class I and class II undergoing elective operation were selected.Patients were grouped into two groups: Group I- Patients received 12.5mg hyperbaric bupivacaine $0.5 \%$ with fentanyl $(25 \mu \mathrm{g})$ intrathecally and Group II- Patients received $10 \mathrm{mg}$ hyperbaric bupivacaine $0.5 \%$ with fentanyl $(25 \mu \mathrm{g})$ intrathecally. All patients were premedicated with Tab. Alprazolam $0.5 \mathrm{mg}$ in the night, the day before the surgery and in the morning on the day of the surgery. Preoperative heart rate, non- invasive blood pressure, respiratory rate and oxygen saturation were recorded. Before lumbar puncture intravenous access was secured with $18 \mathrm{G}$ iv cannula and an infusion of ringer lactate started. Spinal anaesthesia was performed at $\mathrm{L}_{3-4}$ or $\mathrm{L}_{4-5}$ interspace in lateral recumbent position then patient turned to supine position. Achievement of highest dermatome level was observed. Motor blockade was assessed by modified Bromage scale. Oxygen was continuously given to patients via face mask. Time to regress to $T_{12}$ level and duration of analgesia were recorded. All patients were monitored preoperatively, intraoperative and postoperatively for oxygen saturation, non-invasive blood pressure (NIBP) respiratory rate, and heart rate at $3,5,10,15,30,45,60,75,90,150$ and 210 minutes and any complication were recorded. The onset of level 1 Modified Bromage Scale was significantly faster in group 1 than group 2 . Time to regress to $T_{12}$ was significantly higherin group 1 than group 2 and the total duration of effective analgesia was significantly higher in group 1 than group 2. Hypotension was the only adverse effect group $1(40 \%)$ as compared to group $2(6.67 \%)$.
\end{abstract}

KEYWORDS: Subarachnoid Blockade, Bupivacaine, Fentanyl

Use of subarachnoid blockade (SAB) for surgical procedures is a widely accepted anaesthetic technique. Though local anaesthetics initially evoked great enthusiasm, due to their toxicity, they often fell short of providing optimum patient comfort without compromising safety. A combination of a local anaesthetic agent and an opioid used for central neuraxial block prolongs the duration of sensory block without unduly prolonging motor or sympathetic blockade. Opioids and local anaesthetic agents act synergistically to potentiate afferent sensory blockade; thus providing acceptable surgical anaesthesia, without prolonging recovery and increasing the adverse effects. (Ben-David et al., 2000)

The present study was undertaken to compare the efficacy of $0.5 \%$ hyperbaric bupivacaine $(10 \mathrm{mg})$ plus fentanyl $(25 \mu \mathrm{g})$ and $0.5 \%$ hyperbaric bupivacaine $(12.5 \mathrm{mg})$ with fentanyl $(25 \mu \mathrm{g})$ administered intrathecally in elective lower abdominal surgeries.

\section{MATERIALS AND METHODS}

This prospective, double-blind, randomized controlled study was conducted from October 2007 to June
2009. Prior to the commencement of the study, an approval was obtained from hospital ethical research committee. After taking informed and written consent, a total of 60 patients of either sex, aged 30-60 years, and of ASA physical grade I and II, presenting for lower abdominal surgery were included in the study. Patients who had history of hypersensitivity to amide local anaesthetics, heart disease (heart block, arrythmias, left ventricular failure, fixed cardiac output disease), local infection at injection site, coagulation or neuropsychiatric disorders, morbid obesity, pregnancy, spinal deformity and uncontrolled diabetes mellitus were excluded from the study. The patients were randomly divided by means of computergenerated table of random numbers into 2 groups, viz. I and II, each group comprising 30 patients.

Group I- Patients received intrathecal $12.5 \mathrm{mg}$ hyperbaric bupivacaine $0.5 \%$ with fentanyl $(25 \mu \mathrm{g})$.

Group II- Patients received intrathecal 10mg hyperbaric bupivacaine $0.5 \%$ with fentanyl $(25 \mu \mathrm{g})$.

All the patients were examined in the evening before the day of surgery and advised nil per oral (NPO) for

${ }^{1}$ Corresponding author 
8 hours for solid foods and 4 hours for liquids before surgery. All patients received tab Alprazolam $0.5 \mathrm{mg}$ in the night before and at 6 am on the day of surgery. Upon arrival in the operation room, an intravenous access was secured with $18 \mathrm{G}$ cannula and a preloading was done with $10 \mathrm{ml} / \mathrm{kg}$ of Ringer's lactate. Standard monitoring devices such as non-invasive blood pressure, pulse oximetry $\left(\mathrm{SpO}_{2}\right)$ and continuous ECG monitoring was instituted and the baseline parameters were noted. Subarachnoid blockade was performed at L3-4 interspace in lateral recumbent position. The study drugs were prepared by an anaesthesia technician who was not aware of the randomization of study groups.After the subarachnoid administration of drugs, patients were turned supine immediately. Heart rate, continuous electrocardiography, non-invasive blood pressure, pulse oximetry and respiratory rate were monitored pre-operatively, intraoperatively and post operatively at $3,5,10,15,30,45,60,75,90,150$ and at 210 mins. All durations were calculated considering the time of subarachnoid injection as zero. Intraoperative hypotension was taken as systolic blood pressure $<90 \mathrm{~mm}$ of $\mathrm{Hg}$ or $20 \%$ below baseline value and any such episode was treated with administration of oxygen, a bolus of 250 $\mathrm{ml}$ of Ringer's lactae solution over $10 \mathrm{~min}$ and intermittent doses of i.v. injection of mephenteramine $(5 \mathrm{mg})$. Bradycardia or $\mathrm{HR}<50$ beats per minute (bpm) was treated with incremental doses of i.v. injection of $0.3 \mathrm{mg}$ atropine. Intraoperative nausea was treated with i.v. injection of 10 $\mathrm{mg}$ metoclopramide. Shivering was treated with injection tramadol $50 \mathrm{mg}$ i.v. Patients were also monitored for any other side effects like rigor, itching, nausea and vomiting, post dural puncture headache, dizziness, and respiratory depression etc. during the perioperative period.

Level of sensory blockade was tested by loss of pain sensation to a pinprick in the midline using a $22 \mathrm{G}$ blunt hypodermic needle at intervals of 2- min for the first $20 \mathrm{~min}$, and thereafter at intervals of 5-min until no change in level was observed. Onset of sensory block to $T_{10}$ dermatomal level, peak level of sensory block, and duration of sensory block (2-segment regression) were recorded. The degree of motor blockade was assessed by Bromage scale (0-3) as follows: 0-no block, 1-inability to raise the extended leg, 2-inability to flex knee, 3-inability to flex ankle and foot. Time taken for onset of complete motor blockade and time for regression to Bromage scale 1 was also noted. Likewise, sedation was assessed by by a five- point scale: 1-alert and wide awake, 2-arousable to verbal command, 3-arousable with gentle tactile stimulation, 4arousable with vigorous shaking, 5 -unarousable. ${ }^{7}$ Sedation scores were recorded at every 5 -min for first $30 \mathrm{~min}$, and thereafter every $15 \mathrm{~min}$ till the completion of surgical procedure. Analgesia was monitored by using by a 10-point verbal rating scale (VRS), where 0 and 10 represented no pain and worst possible pain respectively. VRS was recorded by an anaesthesiologist unaware of the allocation groups 5 min before subarachnoid blockade, at the start of surgery and then every 15 min interval till the surgery was over. Postoperatively, VRS was recorded half hourly for first $1 \mathrm{~h}$ then one hourly for $12 \mathrm{~h}$ and then three hourly for next $12 \mathrm{~h}$ till $24 \mathrm{~h}$.

After completion of surgery, patient was shifted to post anaesthesia care unit. All the vital and haemodynamic parameters were recorded in the recovery room at $1 \mathrm{~min}, 5$ $\mathrm{min}, 10 \mathrm{~min}, 20 \mathrm{~min}, 30 \mathrm{~min}, 60 \mathrm{~min}$ and $120 \mathrm{~min}$, and thereafter every 4-hourly till 24 hours. Postoperatively sensory and block characteristics were assessed at $30 \mathrm{~min}$ interval $\mathrm{s}$ till $6 \mathrm{~h}$. Time to first dose of rescue analgesia, number of doses of rescue analgesia and the time at which it was repeated was recorded in both groups. The time at which patient demanded first dose of rescue analgesia was the primary end point of this study, because at this time the effect of subarachnoid block had weaned off. The postoperative pain was provided by injection diclofenac sodium, $1.5 \mathrm{mg} / \mathrm{Kg}$ body weight, deep intramuscular, when patients complained of inadequate analgesia or whenever the VRS was $\geq 4$.

At the completion of study, all the observations were compared statistically using unpaired Student's T-test for comparison of parametric data between the two groups and chi-square tests for the non-parametric data using Statistical package for social science (SPSS) version 16 for windows (SPSS Inc, Chicgo, Illinois, USA). p-values < 0.05 and $<0.001$ were considered significant and highly significant respectively.

\section{OBSERVATIONS AND RESULTS}

There were no significant differences between the demographic observations between the two groups.There was no significant difference in mean time of duration of surgery between group $1(81.86 \pm 4.65 \mathrm{~min}$.) and group $2(83.30 \pm 4.45 \mathrm{~min}$.) $(\mathrm{P}>0.05)$. (Table 1$)$ 
BHALEKAR ET AL.: A COMPARATIVE STUDY OF THE TWO DIFFERENT DOSES OF INTRATHECAL HYPERBARIC...

Table 1: Mean age (years), weight (kg), height $(\mathrm{cm})$ and duration of surgery in two groups

\begin{tabular}{|c|c|c|}
\hline Parameters & Group 1 $\mathbf{( N = 3 0 )}$ & Group $\mathbf{2}(\mathbf{N}=\mathbf{3 0})$ \\
\hline $\begin{array}{c}\text { Age (years) } \\
\text { Mean } \pm \text { SD }\end{array}$ & $43.70 \pm 4.17$ yrs. & $42.10 \pm 4.78$ yrs. \\
\hline $\begin{array}{c}\text { Weight (kg) } \\
\text { Mean } \pm \text { SD }\end{array}$ & $61 \pm 11.51$ & $61 \pm 8.43$ \\
\hline $\begin{array}{c}\text { Height (cm) } \\
\text { Mean } \pm \text { SD }\end{array}$ & $149.9 \pm 7.50$ & $147 \pm 7.90$ \\
\hline $\begin{array}{c}\text { Duration of } \\
\text { surgery (min) } \\
\text { Mean } \pm \text { SD }\end{array}$ & $81.86 \pm 4.65$ & $83.30 \pm 4.45$ \\
\hline
\end{tabular}

The mean highest thoracic dermatome blockade level were $\mathrm{T}_{4}$ in both the groups, who received hyperbaric $12.5 \mathrm{mg}$ bupivacaine $0.5 \%+25 \mu \mathrm{g}$ fentanyl intrathecally (group 1) and who received hyperbaric $10 \mathrm{mg}$ bupivacaine $0.5 \%+25 \mu \mathrm{g}$ fentanyl intrathecally (group 2 ). So there was no difference in achieving mean highest thoracic dermatome blockade level in both the groups $(\mathrm{P}>0.05)$. (Table2)

Table 2: Mean Highest Thoracic Dermatome Blockade Level in two groups

\begin{tabular}{|c|c|}
\hline $\begin{array}{c}\text { Group 1 }(\mathbf{N}=30) \\
\text { Mean } \pm \text { SD }\end{array}$ & $\begin{array}{c}\text { Group 2 }(\mathbf{N}=30) \\
\text { Mean } \pm \text { SD }\end{array}$ \\
\hline $4 \pm 0.0$ & $4 \pm 0.0$ \\
\hline
\end{tabular}

The mean onset time to achieve level 1 modified Bromage scale was $3.75 \pm 0.774$ minutes in group 1 and $4.00 \pm 0.83$ minutes in group 2 . So the data shows that the difference is statistically significant as mean time required to achieve level 1 modified Bromage scale was less in group 1 than group $2(\mathrm{P}<0.05)$. (Table 3$)$

Table 3: Mean onset time to achieve Level 1- Modified Bromage Scale in two groups

\begin{tabular}{|c|c|}
\hline $\begin{array}{c}\text { Group 1 }(\mathbf{N}=30) \\
\text { Mean } \pm \text { SD (min) }\end{array}$ & $\begin{array}{c}\text { Group 2 }(\mathbf{N}=\mathbf{3 0}) \\
\text { Mean } \pm \text { SD } \text { (min) }\end{array}$ \\
\hline $3.75 \pm 0.774$ & $4.00 \pm 0.83$ \\
\hline
\end{tabular}

The mean time to regression to $\mathrm{T}_{12}$ was $107.4 \pm$ 6.5 minutes in group who received hyperbaric $12.5 \mathrm{mg}$ bupivacaine $0.5 \%+25 \mu \mathrm{g}$ fentanyl intrathecally and The mean time to regression to $\mathrm{T}_{12}$ was $101.53 \pm 7.33$ minutes who received hyperbaric $10 \mathrm{mg}$ bupivacaine $0.5 \%+25 \mu \mathrm{g}$ fentanyl intrathecally. The mean time to regression to $\mathrm{T}_{12}$ was more in group 1 than group 2. The difference was statistically significant as $\mathrm{P}<0.05$. The mean duration of effective analgesia found was $195.4 \pm 7.29$ minutes in group 1 and182 \pm 9.41 minutes in group 2 . The mean duration of effective analgesia was more in group 1 than group 2. The difference was statistically significant $(\mathrm{P}<0.05)$. (Table 4)

Table 4: Mean time of Regression of Sensory Level and Duration of Analgesia in two Groups

\begin{tabular}{|c|c|c|}
\hline $\begin{array}{c}\text { Time interval } \\
\text { (min) }\end{array}$ & $\begin{array}{c}\text { Group 1 } \\
\mathbf{( N = 3 0 )} \\
\text { Mean } \pm \text { SD }\end{array}$ & $\begin{array}{c}\text { Group 2 } \\
\mathbf{( N = 3 0 )} \\
\text { Mean } \pm \text { SD }\end{array}$ \\
\hline $\begin{array}{c}\text { Time to regression } \\
\text { to } \mathrm{T}_{12}\end{array}$ & $107.4 \pm 6.5$ & $\begin{array}{c}101.53 \pm \\
7.33\end{array}$ \\
\hline $\begin{array}{c}\text { Duration of } \\
\text { effective analgesia }\end{array}$ & $195.4 \pm 7.29$ & $182 \pm 9.41$ \\
\hline
\end{tabular}

The study showed that there was no significant difference in heart rate between group 1 and group 2 preoperatively and at 3,5, 10, 15, 30, 45, 60, 75, 90, 150 and 210 mins $(\mathrm{P}>0.05)$. (Table 5)

Table 5: Mean heart rate at different time intervals in both the groups

\begin{tabular}{|c|c|c|}
\hline $\begin{array}{c}\text { Time interval } \\
\text { (min.) }\end{array}$ & $\begin{array}{c}\text { Group 1 } \\
\text { (per min) } \\
\text { Mean } \pm \text { SD }\end{array}$ & $\begin{array}{c}\text { Group 2 } \\
\text { (per min) } \\
\text { Mean } \pm \text { SD }\end{array}$ \\
\hline Preoperative & $75.96 \pm 8.07$ & $77.03 \pm 7.53$ \\
\hline 3 & $78.96 \pm 7.15$ & $77.73 \pm 7.22$ \\
\hline 5 & $78.06 \pm 6.95$ & $77.86 \pm 7.55$ \\
\hline 10 & $76.40 \pm 7.75$ & $76.80 \pm 8.23$ \\
\hline 15 & $74.90 \pm 7.94$ & $76.76 \pm 7.39$ \\
\hline 30 & $72.73 \pm 14.19$ & $75.73 \pm 8.52$ \\
\hline 45 & $75.43 \pm 8.10$ & $75.96 \pm 8.51$ \\
\hline 60 & $76.53 \pm 9.21$ & $75.90 \pm 7.84$ \\
\hline 75 & $76.63 \pm 8.29$ & $76.06 \pm 8.05$ \\
\hline 90 & $78.43 \pm 7.31$ & $78.53 \pm 5.23$ \\
\hline 150 & $80.43 \pm 7.49$ & $79.56 \pm 5.70$ \\
\hline 210 & $79.13 \pm 6.69$ & $80.26 \pm 5.69$ \\
\hline
\end{tabular}

The study showing that there was no significant difference in oxygen saturation between group 1 and group 2 preoperatively and at 3,5, 10, 15, 30, 45, 60, 75, 90, 150 and 210 mins $(\mathrm{P}>0.05)$. (Table 6) 
BHALEKAR ET AL.: A COMPARATIVE STUDY OF THE TWO DIFFERENT DOSES OF INTRATHECAL HYPERBARIC...

Table 6: Mean oxygen saturation at different time interval in two groups

\begin{tabular}{|c|c|c|}
\hline $\begin{array}{c}\text { Time interval } \\
\text { (min.) }\end{array}$ & $\begin{array}{c}\text { Group 1 } \\
\text { (percent) } \\
\text { Mean } \pm \text { SD }\end{array}$ & $\begin{array}{c}\text { Group 2 } \\
\text { (percent) } \\
\text { Mean } \pm \text { SD }\end{array}$ \\
\hline Preoperative & $98.40 \pm 0.724$ & $98.63 \pm 0.490$ \\
\hline 3 & $98.57 \pm 0.504$ & $98.40 \pm 0.498$ \\
\hline 5 & $98.50 \pm 0.731$ & $98.23 \pm 0.626$ \\
\hline 10 & $98.30 \pm 0.596$ & $98.57 \pm 0.858$ \\
\hline 15 & $98.43 \pm 0.728$ & $98.57 \pm 0.898$ \\
\hline 30 & $98.23 \pm 0.679$ & $98.27 \pm 0.785$ \\
\hline 45 & $98.37 \pm 0.850$ & $98.37 \pm 0.809$ \\
\hline 60 & $98.30 \pm 0.837$ & $98.33 \pm 0.844$ \\
\hline 75 & $98.37 \pm 0.765$ & $98.47 \pm 0.819$ \\
\hline 90 & $98.30 \pm 0.794$ & $98.27 \pm 0.583$ \\
\hline 150 & $98.00 \pm 1.619$ & $98.10 \pm 0.548$ \\
\hline 210 & $98.23 \pm 0.679$ & $98.00 \pm 0.455$ \\
\hline & & \\
\hline
\end{tabular}

There was significant difference (increase) in mean respiratory rate of group 1 and group 2at 3, 5, 10, 90, 150 and 210 minutes $(\mathrm{P}<0.05)$. (Table 7$)$

Table 7: Mean respiratory rate at different time interval in two groups

\begin{tabular}{|c|c|c|}
\hline $\begin{array}{c}\text { Time interval } \\
\text { (min.) }\end{array}$ & $\begin{array}{c}\text { Group 1 } \\
\text { Mean } \pm \text { SD }\end{array}$ & $\begin{array}{c}\text { Group 2 } \\
\text { Mean } \pm \text { SD }\end{array}$ \\
\hline Preoperative & $13.20 \pm 1.3$ & $12.73 \pm 1.31$ \\
\hline 3 & $13.87 \pm 1.22$ & $13.06 \pm 1.25$ \\
\hline 5 & $13.43 \pm 1.25$ & $12.46 \pm 1.04$ \\
\hline 10 & $12.93 \pm 1.11$ & $12.33 \pm 1.09$ \\
\hline 15 & $12.53 \pm 0.89$ & $12.30 \pm 1.02$ \\
\hline 30 & $12.43 \pm 1.16$ & $12.03 \pm 1.24$ \\
\hline 45 & $12.66 \pm 1.26$ & $12.20 \pm 0.96$ \\
\hline 60 & $12.70 \pm 1.17$ & $12.16 \pm 1.08$ \\
\hline 75 & $13.00 \pm 1.17$ & $12.73 \pm 1.08$ \\
\hline 90 & $13.30 \pm 0.95$ & $12.73 \pm 1.01$ \\
\hline 150 & $13.56 \pm 0.93$ & $12.96 \pm 1.06$ \\
\hline 210 & $13.83 \pm 1.11$ & $13.20 \pm 0.80$ \\
\hline
\end{tabular}

12 patients out of 30 patients in group 1 and 2 out of 30 patients in group 2 had developed hypotension; but nausea, vomiting, pruritus and retention of urine were absent in either groups. Hypotension was the only adverse effect found in Group 1 and Group 2. Hypotension was found in $40 \%$ of the cases in group 1, which was significantly higher as compared to $6.67 \%$ of Group 2. (P $<0.05$ ) (Table 8)

Table 8: Perioperative complications in two groups

\begin{tabular}{|c|c|c|c|c|}
\hline \multirow{2}{*}{ Complications } & \multicolumn{2}{|c|}{$\begin{array}{c}\text { Group 1 } \\
\text { (N=30) }\end{array}$} & \multicolumn{2}{c|}{$\begin{array}{c}\text { Group 2 } \\
\text { (N=30) }\end{array}$} \\
\cline { 2 - 5 } & No. & \% & No. & \% \\
\hline Hypotension & 12 & 40 & 2 & 6.67 \\
\hline Nausea & 0 & 0 & 0 & 0 \\
\hline Vomiting & 0 & 0 & 0 & 0 \\
\hline Pruritus & 0 & 0 & 0 & 0 \\
\hline $\begin{array}{c}\text { Retention of } \\
\text { urine }\end{array}$ & 0 & 0 & 0 & 0 \\
\hline
\end{tabular}

\section{DISCUSSION}

Effective pain control, along with minimal adverse effects, is the essential need that dictates the choice of local anaesthetic agent during a neuraxial blockade. Bupivacaine; a long acting local anaesthetic agent was first introduced in the year 1957 by Eckenstam, but its clinical use was started in the year 1963 by Telivuo. (Eckenstam et al., 1956) (Telivuo, 1963) It has a considerably long duration of action. (Widman, 1964) (Ekblom et al., 1966) Fentanyl, a synthetic lipophilic potent opioid, which is less toxic than morphine, has been found to prolong the duration of sensory block without prolonging motor or sympathetic blockade. (Wang, 1993) Side effects of opioid anaesthetics such as respiratory depression, both early and late, are common with intrathecal morphine, but are rare with fentanyl. (Davies et al., 1980) Fentanyl and bupivacaine have synergistic effect and provide analgesia.

In this study, 60 patients were randomly divided into two groups i.e., group 1 and group 2 of ASA class I and class II. There was no significant difference in demographic details between the two groups. Literature shows that hyperbaric solution gravitates to the thoracic hollow after intrathecal injection and achieves thoracic $\left(\mathrm{T}_{6}\right)$ dermatomal level of spinal anaesthesia (Sinclair et al., 1982). In the present study, highest thoracic dermatome achieved in group 1and group 2 was $\mathrm{T}_{4}$ dermatomal level. (Bernat et al., 2003) found that the sensory block reached level $\mathrm{T}_{4}$ in patients who received intrathecal $13 \mathrm{mg}$ hyperbaric bupivacaine $0.5 \%+15 \mu \mathrm{g}$ fentanyl. (Bernat et al., 2007) (Grewal et al., 2003) also found $\mathrm{T}_{4}$ were the highest dermatome level achieved in their study. 
In this study, it was observed that the mean onset time to reach level-1 modified Bromage scale was $3.75 \pm$ $0.774 \mathrm{~min}$ in group 1 and $4.00 \pm 0.83 \mathrm{~min}$ in group 2 .With lidocaine $2 \%$ plain and lidocaine $2 \%$ with glucose $8 \%$ observed that mean time to reach level-1 Modified Bromage scale was $10 \mathrm{~min}$. in both the groups. (Harbers et al., 1994) Alonso Chico A. et al. demonstrated that Fentanyl $12.5 \mu \mathrm{g}$ added to low-dose bupivacaine (5mg) intrathecally provides better surgical anaesthesia and increased reliability of block than intrathecal fentanyl 7.5 or $10 \mu \mathrm{g}$. (Alonso Chico et al., 2003) (Grewal et al., 2003) were also reported that duration of sensory block was significantly longer with hyperbaric $15 \mathrm{mg}$ bupivacaine 0.5 $\%+25 \mu \mathrm{g}$ fentanyl than hyperbaric $10 \mathrm{mg}$ bupivacaine 0.5 $\%+25 \mu \mathrm{g}$ fentanyl this supports our study in which it was found that time to regress to $T_{12}$ level was significantly greater in group 1 (107.4 $\pm 6.5 \mathrm{~min}$.) than group 2 (101.53 \pm $7.33 \mathrm{~min}$.). Thus larger doses of hyperbaric bupivacaine $0.5 \%$ prolong the time taken to regress to $T_{12}$.

Grewal et al., (2003) found that the mean time to first requirement of analgesia was lower with hyperbaric $10 \mathrm{mg}$ bupivacaine $0.5 \%+25 \mu \mathrm{g}$ fentanyl than $12.5 \mathrm{mg}$ and $15 \mathrm{mg}$ hyperbaric bupivacaine $0.5 \%+25 \mu \mathrm{g}$ fentanyl. (Grewal et al., 2003) (Bernat et al., 2007) observed that postoperative analgesia lasted longer in patients who received $13 \mathrm{mg}$ hyperbaric bupivacaine with $15 \mu \mathrm{g}$ fentanyl than in patient who received $14 \mathrm{mg}$ hyperbaric bupivacaine only with a mean duration of $(194 \pm 19)$ minutes. (Bernat et al., 2007) In present study, the mean time to first requirement of analgesia was significantly more in group 1 (195.4 \pm 7.29 min.) than group 2 (182.0 \pm 9.41$)$, this supports that larger dose of hyperbaric bupivacaine $0.5 \%$ prolongs the duration of analgesia irrespective of the addition of fentanyl.

Choi et al., (2000) also confirmed that $12 \mathrm{mg}$ of hyperbaric bupivacaine was the best dose for bupivacaine only for cesarean deliveries, whereas only $8 \mathrm{mg}$ of $0.5 \%$ hyperbaric bupivacaine, when combined with $10 \mu \mathrm{g}$ of fentanyl, was sufficient for spinal anaesthesia in cesarean deliveries. In this study also, it was observed that the effective analgesia in both group 1 (12.5mg hyperbaric bupivacaine with $25 \mu \mathrm{g}$ of fentanyl) and group 2 (10mg hyperbaric bupivacaine with $25 \mu \mathrm{g}$ of fentanyl) during intraoperative period. Grewal et al., (2003) observed slight fall in heart rate from base line, but there was no episode of bradycardia they also observed no significant decrease in oxygen saturation. In this study also there was no significant decrease in heart rate and oxygen saturation between the two groups. Varassi et al., (1992) observed respiratory depression with higher dose of fentanyl $(50 \mu \mathrm{g})$ in the intrathecal space. Grewal et al., (2003) could not find respiratory depression with low dose of fentanyl $(25 \mu \mathrm{g})$. Similarly in the present study, there was no respiratory depression was found in both the group. Simultaneous use of intrathecal low dose opioids does not add to the hypotension and collapse associated with the use of intrathecal local anaesthetics. (Cousins et al., 1979) (Scott et al., 1979)

Addition of fentanyl with local anaesthetics for intrathecal use was also mentioned by Alonso. Alonso Chico et al., (2003) in elderly patients and is effective for maintaining greater hemodynamic stability, allowing use of a lower dose of hyperbaric bupivacaine and reducing the need for intravenous ephedrine during surgery. (Choi et al., 2003) (Goel et al., 2003) reported that intrathecal opioids added to low-dose local anaesthetics produce a synergistic effect without increasing the sympathetic block or delaying discharge. The most common complications following subarachnoid block is hypotension. (Greene et al., 1993) (Moore et al., 1966) (McClure et al., 1988) This has been predicted by experimental work which shows that the decrease in sympathetic efferent activity after spinal anaesthesia with bupivacaine is dose related and intrathecal fentanyl neither by itself nor in combination with bupivacaine causes any depression of efferent sympathetic activity. (Wang, 1993) (Ben David et al., 2000) observed that $5 \mathrm{mg}$ bupivacaine with $25 \mu \mathrm{g}$ fentanyl provided spinal anaesthesia for cesarean delivery with less hypotension, vasopressor requirements, and nausea than spinal anaesthesia with $10 \mathrm{mg}$ bupivacaine.

They supported the point that the decrease in sympathetic efferent activity after spinal anaesthesia is related to the dose of bupivacaine, and intrathecal fentanyl causes no further depression of the efferent sympathetic activity. Grewal et al., (2003) observed 40\% hypotension in patient who received hyperbaric $15 \mathrm{mg}$ bupivacaine $0.5 \%+$ $25 \mu \mathrm{g}$ fentanyl and $4 \%$ in patient who received hyperbaric $10 \mathrm{mg}$ bupivacaine $0.5 \%+25 \mu \mathrm{g}$ fentanyl and $20 \%$ in patient who received hyperbaric $12.5 \mathrm{mg}$ bupivacaine $0.5 \%$ $+25 \mu \mathrm{g}$ fentanyl. These findings support the findings of the present work. Comparison of hypotension between patient who received $10 \mathrm{mg}(6.67 \%)$ and $12.5 \mathrm{mg}(40 \%)$ hyperbaric 


\section{BHALEKAR ET AL.: A COMPARATIVE STUDY OF THE TWO DIFFERENT DOSES OF INTRATHECAL HYPERBARIC...}

bupivacaine $+25 \mu \mathrm{g}$ fentanyl so hypotension is significantly more with larger dose of hyperbaric bupivacaine.

Grewal et al., (2003) observed pruritus (16\%), nausea (12\%) but not observed any episode of vomiting. In present study no episode of nausea, pruritus and vomiting was observed. Choi et al., (2000) also noted that there is no significant difference in incidence of other adverse effects such as pruritis, shivering or nausea/vomiting between the two groups.

\section{CONCLUSION}

The present study concludes that intrathecal administration of $10 \mathrm{mg}$ hyperbaric bupivacaine $0.5 \%$ with fentanyl $(25 \mu \mathrm{g})$ is as effective as $10 \mathrm{mg}$ hyperbaric $0.5 \%$ bupivacaine with fentanyl $(25 \mu \mathrm{g})$ for lower abdominal surgeries in terms of blockade of dermatomes, better haemodynamic stability and less perioperative complications.

\section{REFERENCES}

Alonsco Chico A., Cruz Parlos P. and Aivarez Grau J., 2003. Comparison of hemodynamic response in subarachnoid anesthesia with bupivacaine vs bupivacaine with fentanyl in traumatology surgery in elderly patients. Rev Esp Anesthesiol Reanim, 50(1): $17-22$.

Ben-David B., Miller G., Gavriel R. and Gurevitch A., 2000. Low dose bupivacaine-fentanyl anaesthesia for caesarian delivery. Reg Anesth Pain Med., 25(3):235-9.

Bernat G.J., Gallego G.J. and Albengochea Containa A., 2007. Hyperbaric bupivacaine: a randomized double-blind trial of different doses with or without fentanyl for cesarean section under spinal anesthesia. Rev Esp. Anestesiol Reanim, 54(1): 410.

Choi D.H., Kim J.A. and Chung I.S., 2000. Comparison of combined spinal epidural anesthesia and epidural anesthesia for cesarean section. Acta Anaesthesiol Scand, 44: 214-9.

Cousins M.J. and Mather L.E., 1979. Intrathecal and epidural administration of opioids. Lancet, 1: 11.
Davies G.K., Tolhurst-Cleaver L.L. and James T.L., 1980 CNS depression after intrathecal morphine. Anesthesiology, 52(3): 280.

Eckenstam A.F.B., Egner B., Ulfendahl L.R., Dhungr K.G. and Oljeund O., 1956. Trials with carbocaine: A new local anaesthetic drug. British Journal of Anaesthesia, 28(11):503.

Ekblom L. and Widman B., 1963. LAC-43 and tetracaine in spinal anesthesia. A controlled clinical study. Acta Anaesth Scand 1966; 23: 419-25.3. Telivuo L. A new long acting local anaesthetic solution for pain relief after thoractomy. Ann Chir Gynaecol Fenn, 52:513-20.

Goel S., Bhardwaj N. and Grover V.K., 2003. Intratheacal fentanyl added to intratheacal bupivacaine for day case surgery: a randomized study. Eur. J. Anaesthesol, 20(4): 294-7.

Greene N.M. and Brull S.J., 1993. The cardiovascular system in Greene NM, Brull SJ. eds. Physiology of spinal anaesthesia Baltimore: Williams and Wilkins, 85-199.

Grewal P., Katyal S., Kaul T.K., Narula N. and Grewal A., 2003. Comparative study of effects of fentanyl with different doses of bupivacaine in subarachnoid block. J. of Anaesthesiology Clinical Pharmacology, 19(2): 193-197.

Harbers J.B.M., Stienstra R., Gielen M.J.M. and Cromheecke G.J., 1994. A double blind comparision of lidocaine $2 \%$ with or out glucose for spinal anaesthesia. with Acta Anaeesthesiologica Scandinavica, 39(7):881-84.

McClure J.H. and Wildsmith J.A., 1988. Aspects of spinal anaesthesia in Kaufman Led. Anaesthesia Review 5. Edinburg: Churchill Livingstone, 269-84.

Moore D.C. and Bridenbaugh L.D., 1966. Spinal (subarachnoid block) a review of 11574 cases. JAMA, 195(11): 907-12

Scott D.B. and McClune J., 1979. Selective epidural analgesia. Lancet, 313:1410-11.

Sinclair C.J., Scott D.B. and Edstrom H.H., 1982. Effect of trendelenberg position on spinal analgesia with 
BHALEKAR ET AL.: A COMPARATIVE STUDY OF THE TWO DIFFERENT DOSES OF INTRATHECAL HYPERBARIC...

hyperbaric bupivacaine. Brit J Anaesth, 54(5): 497-500.

Telivuo L., 1963. A new long acting local anaesthetic solution for pain relief after thoractomy. Ann Chir Gynaecol Fenn., 52:513-20.

Varrassi G., Celleno D. and Capogna G., 1992. Ventilatory effects of subarachnoid fentanyl in the elderly. Anaesthesia, 47:558-62.
Wang C., Chakrabati M.K. and Whitman J.G., 1993. Specific enhancement by fentanyl of the effects of intrathecal bupivacaine on nociceptive afferent but not on efferent pathways in dogs. Anesthesiology, 79: 766-73.

Widman B., 1964. Clinical trial of a new local anaesthetic (LACA3) with the aid of the pin-prick \& Ninhydrin methods in finger blocks. Acta Anaesthesiol Scand, 8:219-26. 